\title{
Descartes... a distancia
}

Este ensayo que nos ha cuviado el notable pensador y crilico español, doctor César Barja, fué escrito a propósito del libro argentino Escritos en honor de Descartes. La REVISTA IBEROAMERICANA, consagrada específicamente a la literatura de Iberoamirica, acoge con entusiasmo los estudios que, como los de los doctores Barja y Vitier, tienten relación con las actividades filosóficas que en ella se desarrollan, por ser afines a su litcratura. Altora y sientpre, toda labor de alto valor que en este campo se produsca en Iberoamcrica encontrará eco de simpatia en la REVISTA IBEROAMERICANA y será comentada por colaboradores de reconocida competencia.

Difícil tarea la de decir a qué altura nos hallamos hoy respecto a Descartes; fijar el litgar preciso ocupado por la filosofía de tan ilustre personaje entre las encontradas corrientes del pensamiento contemporáneo. El simple hecho de reunirse en París, en el verano de 1937 , varios centenares de filósofos y científicos alli llegados de los cuatro puntos cardinales para asistir a las sesiones del Congreso Descartes (IX Congreso Internacional de Filosofia), precisamente al cumplirse el tercer centenario de la aparición del Discours de la Méthode, haría por si sólo suponer que la filosofía cartesiana sigue todavía en pie, en plena posesión de su original vitalidad. La suposición, sin embargo, queda desautorizada por los resultados mismos del Congreso. 
En las palabras de uno de los representantes en la magna asamblea: "Ce Congrès, qui devait magnifier Descartes et son oeuvre toute fondée sur la raison, la logique et les mathématiques, fut au contraire une manifestation de défiance contre la valeur de la raison, de la logique et les mathématiques". Asi en un lugar. Y en otro: "Le Congrès Descartes a démontré qu'il existe de nos jours, parmi les philosophes et les savants, une défiance toujours plus grande contre la raison et sa clarté, dont Descartes lui-même avait fait le fondement de toute vérité et de toute realité". (I)

Sin duda, mucha de la dificultad que se presenta al querer darse cuenta exacta de la vigencia que haya de atribuirse a la filosofía cartesiana resulta del carácter mismo de esa filosofía. Descartes pasa, en la opinión más vulgarizada, por ser no sólo un buen escritor, sino, sobre todo, un pensador claro; su filosofía pasa igualmente por un modelo de pensamiento claro y preciso. $\mathrm{Y}$ no hay apenas que observar cuánto ha contribuido a crear una tal impresión el hecho mismo de presentarse Descartes como un hombre ordinario y modesto, escribiendo en una manera familiar, más el haber dado a su filosofía un aire de cosa de sentido común y, comó en el famoso Método, de experiencia vivida, a modo de confesión intelectual. Indudablemente, si para leer a cualquiera de los grandes filósofos europeos parece requerirse capacidad y esfuerzo superiores, para leer a Descartes basta sólo, diríase, con un tanto de sentido común. Sentido común que por ser "la cosa del mundo mejor reparti$\mathrm{da}$ ", todos en principio poseen y a todos en principio capacita por igual para leer, y para leer entendiendo, a Descartes. Difícilmente se hallaría otra filosofía especializada más ligada en la mente de las gentes a esta nota de muudanalidad, de cosa fácil y clara. Ni siquiera la del mismo Bergson. La línea divisoria entre lo meramente literario y lo específicamente filosófico es aquí tan tenue, tan indecisa, que acaba por perdérsela de vista. Descartes es capítulo fundamental de toda historia de la lite- 
ratura francesa clásica, un poco después de Montaigne y casi al lado de Corneille.

Pero si tal es la común impresión, otra, muy distinta, es la verdad. Y la verdad es que la filosofía de Descartes es todo, menos clara. Más bien es una filosofía, si no precisamente difícil, sí harto problemática, y más aún que problemática, en extremo confusa. - Su misma aparente claridad —claridad de superficie-, no es claridad que ilumine; es, por el contrario, claridad que oscurece la dificultad y complejidad de los problemas planteados y conceptos de que se sirve. Filosofía, en fin, a base de equívocos. El equívoco es, en efecto, la sustancia de esta filosofía fácil y clara. Repetidas veces notado este carácter de la filosofía de Descartes, ha sido más recientemente analizado tan completa y tan detalladamente por el autor de la Psychologic der Weltanschaniningen, Karl Jaspers, (2) que toda insistencia sobre el particular es innecesaria. Bastará con sólo recordar que es ese mismo equívoco lo que hizo y sigue hacienclo posible que todos, cada uno desde su particular punto de vista, por contradictorios que los varios puntos de vista puedan ser, reclame a Descartes como suyo, y, cada uno a su manera, se considere en la línea del pensamiento de este autor. Católicos y librepensadores, conservadores y liberales, todos hallan soporte para sus ideas en la filosofía de Descartes. Y Descartes mismo, el hombre que se vela tras el equívoco de esa filosofía, ¿qué fué en definitiva? Entre teología y filosofia, Edad Media y Renacimiento; entre el principio de autoridad - sociedad, Iglesia, Estado- y el principio de libertad, ¿dónde, en realidad, está exactamente Descartes? En vano los intérpretes racionalistas, liberales y revolucionarios del cartesianismo intentan convencernos de que teología, principio de autoridad y demás zarandajas religiosas y conservadoras que en los escritos de Descartes aparecen son... eso, puras zarandajas, a modo de taparrabos intelectuales con que el astuto y cauteloso pensador trataba de protegerse a sí mismo, cubriendo la osadía de sus ideas 
revolucionarias. Lo cierto es que tales zarandajas dábanse en el hombre Descartes y danse en su filosofía como cosa fundamental. El Dios de esa filosofía podrá ser todo lo abstracto e idea que se quiera (y no lo es tanto, ni mucho menos, como ciertas gentes lo desearan); es, en todo caso, la fuente primera y última de veracidad a la base de esa filosofía, y garantía de toda otra veracidad, del mundo de la razón y del mundo de las cosas físicas. Es la indubitable realidad de la que en última instancia deriva la indubitabilidad del mismo cogito, ergo sum-“Car sans la connaissance de ces deux vérités (existencia y veracidad de Dios), je ne vois pas que je puisse jamais être certain d' aucune chose" ("Méditation troisième"). Igual, el principio de attoridad -sociedad, Iglesia, Estadoes la garantía necesaria para una vida de acción y de moral práctica, moral que Descartes es el primero en darse cttenta ser imposible deducirla en cada instancia de un mero postulado de razón puras

Sirviendo de pórtico a la filosofía de Descartes está el Discours de la Méthode-un método, un camino pour bicn conduire sa raison et chercher la vérité. En busca de ese camino hacia el reino de la verdad había dos principales vías a'seguir, dos direcciones. La una, hacia afuera, en marcha directa hacia las cosas; la otra, hacia adentro, en dirección del propio sujeto pensante. Por la inseguridad que consigo lleva la primera vía (los sentidos son falaces), Descartes se decide por la segunda. Recorriéndola, halla la razón a lo largo de esa vía lo que puede hallar: hállase a sí misma como dudando, es decir, como pensando, $y$, por consiguiente, como siendo. Tampoco el sujeto que piensa es más que eso: una cosa pensante. Aislada, reclusa dentro de sí misma, es cuanto por de pronto la razón puede dar de sí. No es poco; con ello ha adquirido la 
razón conciencia de sí misma, de su independencia, de su autonomía. Antes la razón pensaba; ahora no sólo piensa sino que, más importante, sabe que piensa.

Como en toda filosofía; pero más aún que en la mayor parte de ellas, danse en la de Descartes dos aspectos, dos elementos, que importa distinguir. De una parte tenemos una serie de principios, un cierto contenido de temas y de conceptos: un sistema. Cualquiera que pueda ser la verdad de ese sistema, acaso sea lo menos importante en el caso presente. Acaso sea también lo menos importante en toda filosofía, si atendemos a la atinada observación de Simmel al suponer que, como él dice, "quizá no es el criterio de la verdad el más adecuado para decidir del valor de una filosofía”, (3) ya que todas ellas, en efecto, apreciadas por un tal criterio de pura y simple verdad objetiva (criterio en sí mismo más científico que filosófico) resultan en extremo problemáticas, trátese de las ideas de Platón o trátese de la voluntad de Schopenhauer. Más importante es, sin duda, el segundo aspecto o elemento, representado no ya por contenido alguno específico de temas ni por la estricta verdad objetiva de los principios y conclusiones, sino por la proyección ideológica en que dicha filosofía se orienta, es decir, por el espíritu que la informa, revelación a su vez de una cierta manera de reaccionar frente a la vida y los problemas de la vida. En este sentido cabe decir que la filosofía de Descartes, el cartesianismo, es ante todo, y muy marcadamente, una cierta dirección ideológica, un espíritu, lo mismo que lo son el platonismo y el nietzscheanismo.

Ahora bien; por lo que al cartesianismo se refiere, lo característico de ese espíritu resulta precisamente -la cosa es bien sabida- de esa dirección hacia adentro en que se proyecta, de la interiorización en que se orienta. Interiorización en la que, como acabamos de decir, la razón acaba por adquirir conciencia de sí misma y como tal se afirma, con propia autonomía. En términos de valores, es el primado de la razón lo que aquí ante 
todo se afirma. De la razón y por la razón saldrá luego todo lo demás. El cogito, crgo sum no es sólo un principio èntre tantos otros; es algo así como el punto de apoyo que Arquímedes pedia para remover la tierra. "Archimède, pour tirer le globe terrestre de sa place et le transporter en un autre lieu, ne demandait rien qu'un point qui fût ferme et immobile; ainsi j'aurait droit de concevoir de hautes espérances si je suis assez heureux pour trouver seulement une chose qui soit certaine et indubitable" ("Méditation deuxième"). Asegurado en la indụbitable verdad del cogito, ergo sim, en torno a él y partiendo de él, Descartes pretenderá nada menos que construir a base de deducciones racionales el universo entero, desde Dios para abajo. Enorme arquitectura levantada sobre el pilar de un primer y único principio de razón pura. Son un pensamiento y una filosofía imparciales los de Descartes, y el soberano de ese vasto imperio no es ni esta ni aquella cosa o fuerza material, ni siquiera es el ser del propio yo pensante en la complejidad de su realidad viva, ni siquiera es la razón aplicada a este o el otro menester vital; es la sola razón de por sí, la pura razón, la razón pura que se piensa a sí misma - agua cristalina brotada del vacío y que salta en el vacio. A un tal espíritu de la filosofía cartesiana le llamamos racionalismo, y padre del racionalismo moderno llamamos a Descartes, y ambas cosas no sin razón. Y no hay que decir ahora la enorme influencia que como tal racionalismo ha ejercido el espíritu de la filosofía cartesiana en la historia del pensamiento moderno. En él se inspira y con él se anima ese pensamiento durante casi trescientos años, llámesele al resultado racionalismo, idealismo, subjetivismo, o como se quiera. $Y$ no sólo el pensamiento; la vida misma de Europa es dominada y arrastrada por ese espíritu, sígasele aún llamando racionalismo, o llámesele liberalismo, individualismo, espiritu revolucionario, o como se quiera. Las etiquetas cambian; los vinos son unos más puros y generosos que otros; los vapores del alcohol, sin embargo, son en su esencia los mismos. Pero 
más aún; hoy mismo, en pleno desfogue de lo que, si no lo es, parece burdo y bruto irracionalismo, ¿no podria pensarse que el tal irracionalismo no es, en el fondo, más que el otro lado, grotesco y caricaturesco, de ese mismo espíritu del racionalismo cartesiano? Porque al fin y al cabo habrá que convenir en que el hombre de inteligencia obtusa verá poco $\mathrm{y}$, apreciado por otros criterios, lo verá mal; desde su punto de vista, sin embargo, lo que ve lo ve tan clara y distintamente como el hombre de inteligencia aguda ve clara y distintamente lo que ve, cada uno, naturalmente, según las entendederas que Dios le haya dado. $\mathrm{Ni}$ fueron exactamente sólo genialidades, ni siquiera verdades, las que el propio Descartes, con toda su lucidez de pensamiento, sacó de su razón. Sí; de la razón abandonada a sí misma, de la razón pura, brota la verdad, pero de ella brota igualmente el error; lo más noble y lo más monstruoso.

Sólo por razón del espiritu de la filosofía cartesiana percibimos a la vez que el lado favorable, el lado adverso de esa filosofía; lo que en ella hay para la época actual de estímulo, pero también lo que en ella hay de advertimiento.

Siguiendo la orientación marcada por el espiritu de esa filosofía en lo que al primado de la razón se refiere, sentimos también nosotros el respeto de la razón; reconocemos su valor y afirmamos sus derechos. Cuantas dudas puedan suscitarse sobre la validez última de la razón como criterio de verdad, no destruyen, por mucho que puedan oscurecerla, la realidad mismia del hecho. $Y$ el hecho es que a ese respeto de la razón, su valor y sus derechos va ligada esencialmente nuestra idea de vida culta, de perfeccionamiento y de progreso. Aún más; a los derechos de la razón van ligados nuestro sentido de libertad y nuestro sentimiento de dignidad. Son los derechos de la razón, en definitiva, nuestros derechos como hombres; rechazados los 
unos quedan automáticamente rechazados los otros. Si no fuera por el favor que desde hace ya años viene gozando, en la filosofía y en la vida, en las teorías de la una y en las prácticas de la otra, la tendencia a rebajar el valor de la razón, no valdría siquiera la pena de hablar de todo esto, tan elemental es todo ello. Por eso, elemental y todo, habrá que recordar que, como quiera que sea, a la razón será necesario recurrir siempre en última apelación, aun en aquellos cạsos en que es la validez de la razón misma lo que está en litigio. Cuando no sirva para darnos cuenta de la razón de las cosas, servirá por lo menos para darnos cuenta de su sinrazón.: $\mathrm{Ni}$ con los pies, lo que se dice con los pies, ni con el corazón, lo que se dice con el corazón, ha pensado en rigor nadie nada.

Respeto, pues, a la razón, reconocimiento de su valor y afirmación de sus derechos. En lo que Descartes y el cartesianismo han contribuido a crear o a acentuar ese respeto, ese valor y esos derechos - hasta ahí somos todos cartesianos; hasta ahí llegamos en nuestra apropiación del espíritu de la filosofía cartesiana. : Ello parece indudablemente bien poco, y de discutible autenticidad, pero quizá la época nuestra no da más de sí en ese respecto. Al contrario; apercibidos, como decíamos hace un momento, si del lado favorable; también del lado adverso y peligroso del espíritu cartesiano, resístese nuestra época a dejarse arrastrár por la tendencia latente en el cartesianismo a desarticular la razón de la vida, sospechando, no ciertamente sin causa, que la supuesta claridad de la razón como criterio de verdad ("toutes les choses que nous concevons fort clairement et fort distinctement sont toutes vraies", "Méditation troisième") puede ser tan engañosa y tan falaz como el mismo testimonio de los sentidos; que si el mundo que éstos nos descubren puede ser falso, el que la razón pura nos construye puede ser igualmente falso, más irreal, e infinitamente más peligroso. La misma razón que nos hace cautelosos en nuestro trato diario con el mundo percibido por los sentidos, acaba por hacernos igualmen- 
te cautelosos frente a las construcciones de una razón abandorada a sí.misma, sin más guía ni más control que los que puedan resultar de la mera coherencia lógica de las ideas. Así, abandonarnos a la razón, nos parece una peligrosa ingenuidad.

No nos seduce tampoco la belleza esquemática, de conceptos desnudos, de ese mundo espectral construído por la razón desarticulada de la vida y al margen de la vida. A toda esa belleza linear de abstracto $y$ frío encuadrillado geométrico preferimos la menos pura pero al fin más humana, más atrayente y más jugosa belleza de las realidades vivas, cualesquiera que puedan ser sus imperfecciones.

Nos resistimos, sobre todo, a hacer de la vida el molde de formas fijas y eternas a que por propia naturaleza tiende la razón abandonada a sólo las exigencias de un pensar lógico Cierto es que hay que pensar la vida, pero hay que pensatla precisamente así, como vida, no como cosa muerta; como realidad viviente con toda su cambiante riqueza de contenidos y de formas, como corriente que fluye, no como laguna estancada. Y eso, laguna de agụas estancadas, mundo concluso donde todo ha stucedido ya, es lo que tiende a ser cada filosofía de la ráón pura, y es lo que cada una de esas filosofías aspira a hacer de la vida. Empieza la razón por ofrecernos un mundo mágico de libertad y amplitud infinitas, y con él nos seduce. Quietı se decida a instalarse en ese mundo, sin embargo, acabará por encontrarlo rigido, angosto, y pobre, en último término, más rígido, más angosto y más pobre que el mundo de las cosas que pretende sustituir.

Decididamente, ha pasado para nosotros la hora del cartesianismo, en lo que el cartesianismo significa espiritu disociativo, tendencia a desligar la razón de la vida, sustituyendo a las realidades de ésta las abstracciones de aquélla. Por eso también, más que de seguir en la línea del espíritu cartesiano; línea que al prolongarla acaba por llevarnos al vacío de un mundo de puros e inertes conceptos de la razón, ha de tratarse para nos- 
otros, como ya en efecto se está tratando, a la vez que de recoger lo que en ese espíritu hay de aprovechable, de corregir las deficiencias que en él se advierten, deficiencias que son otras tantas fallas del cartesianismo, como probablemente lo fueron del hombre Descartes. Como más evidentes, la falta de sentido histórico y la falta de sentido de la vida del ser humano, no sólo como mera cosa pensante, sino como humanidad viviente. Sentido éste de la vida que es sentido de la vida como cuestión de destino, con todo el dramatismo que semejante sentido o sentimiento lleva consigo, como lo lleva toda vida vivida. Ante un tal sentido del destino; ante la duda despertada por un tal sentido - -duda de Pascal, de Kierkegaard, de Nietzsche, de Unamuno y de tantos otros-, aparece toda la duda metódica de la filosofía cartesiana como pueril ejercicio de fría especulación intelectual, sin alma, sin entrañas. No una filosofía más de la razón pura que nos diga que somos, cosa al fin por nadie dudada seriamente, ni por el propio Descartes, sino una filosofía de la vida, de la existencia, que nos diga lo que somos, es lo que pide, porque lo necesita, nuestra época.

Sirvió de causa, o quizás más bien de pretexto, a las anteriores, un tanto descosidas consideraciones, la lectura del volumen Escritos en honor de Descartes en ocasión del tcrcer centenario del "Discurso del Método" (La Plata, I938, 337 pp.), colección de trabajos sobre múltiples aspectos del pensamiento filosófico y científico de Descartes, y digno homenaje con que la Universidad Nacional de La Plata quiso honrar la memoria del ilustre pensador en tan señalada ocasión. El no conocer directamente otras publicaciones semejantes aparecidas en Iberoamérica en celebración de ese tercer centenario, nos impide referirnos a ellas. Aun así, con sólo el presente volumen a la vista, la impresión que resulta de la lectura de los trabajos que lo com- 
ponen, es en extremo favorable. De los trabajos mismos podrán estimarse, como es natural, unos más que otros, y por únos más que por otros. Pero aparte una nota de superior calidad común a todos o la mayor parte de ellos, el simple hecho de una publicación como ésta reviste particular importancia, precisamente como revelación de un vivo interés por los estudios filosóficos y prueba de un ambiente propicio para esta clase de labor inteléctual en Iberoamérica. Que la ocasión la hubiera ofrecido Descartes o cualquiera otro autor o acontecimiento del pensar filosófico, es de por si lo de menos. Como nacida en Europa, América habrá de continuar aún por años a Europa. Pero por debajo de esa stiperficie de vida y pensamiento europeos, otra realidad se irá abriendo paso, como de hecho hace ya tiempo viene abriéndoselo, realidad que al fin acabará por imponerse, y como en la literatura, el arte y la vida práctica, hallará también exprésión en un modo de pensar filosófico, en unia cierta actitud filosófica. Dentro de la supuesta unidad y universalidad filosóficas caben al fin, como la historia lo evidencia, los más variados modos y matices, cada uno reflejo de una particular manera de vida práctica y cspiritual. En América misma sabemos ya bastante de la realidad de esa manera en la Norteamérica de la hora actual; $y$ como expresión de ella tenemos también una cierta filosofía (la de Dewey, por ejemplo), amén de mucha psicología, no poca ética y su tanto de estética. De la manera de vida práctica y espiritual de Iberoamérica, en cambio, en términos de pensamiento y expresión filosóficos, sabemos mucho menos, y aun eso más a través de la literatura y del mecanismo de la vida diaria.

Descle este punto de vista uno se pregunta, con curiosidad no ciertamente exenta de inquietud, cuál puede ser el significado de un filósofo y una filosofía como Descartes y el cartesianismo en la realidad de la vida iberoamericana: En relación con esta pregunta nos llaman desde luego la atención las observaciones del señor Anibal Sánchez Reulet, autor del trabajo "Des- 
cartes, hombre moderno", incluído en el volumen-homenaje de que tratamos, en declaraciones como éstas: "En Descartes -dice- no hay más que desprecio para todo lo que sea tradicional. . Ese menosprecio por todo vivir tradicional es uno de los rasgos decisivos del alma moderna... Lo sienten, sobre todo, los americanos. En rigor, lo que hoy se llama americanismo está potencialmente contenido en la concepción cartesiana, racionalista y anti-tradicional. La americanización de Europa comenzó, pues, hace tres siglos con Descartes" (p. 280).

Se advierte desde luego el sentido plenamente moderno atribuído a Descartes por el señor Reulet. "Descartes... f fué el primer hombre verdaderamente moderno" (p. 275). Tal como lo presenta el autor, resulta Descartes, efectivamente, punto de convergencia de cuantos afanes, motivos y tendencias-se agitaban en el seno de la vida europea, de la espontánea como de la reflexiva, en su paso de la Edad Media a la Edad Moderna, todo lo cual Descartes recogió en sí, y a todo lo cual él dió una orientación de modernidad, marcando así el modo de vida que desde el Renacimiento llega hasta nosotros. Sin que ello obste, por otra parte, para que el mismo autor reconozca luego, al final de su estudio, el hecho de que "el método cartesiano ha perdido hace tiempo su vigencia" (p. 286). El "método", no el "modo de vida"; es la razón cartesiana que ha perdido su utilidad, sustituída por la razón histórica.

La tesis misma del señor Reulet peca acaso de ser excesivamente unilateral; de no ver a Descartes más que por un lado de su personalidad y de su pensamiento. $Y$ es que visto por los dos lados, nos encontraríamos una vez más, respecto a este tema de su modernidad, con uno de esos equívocos en que, como dicho queda, tanto abunda la filosofía del ilustre pensador. Otros de los autores representados en el presente volumen lo advierten así, y con sus apreciaciones habrá de comparar el lector las del señor Reulet. Por ejemplo, el autor del trabajo "De sabiduría griega en Descartes", scñor R. Saboia de Me- 
deiros, cn declaraciones como ésta: "Descartes -dice-- vive así distendido entre dos mundos. $\mathrm{Y}$ el cartesianismo resulta uno de los más ambiguos e indefinidos sistemas. Tradicional y no tradicional; innovador y no innovador. Todo ello sin la conciencia cle su autor" (p. 274). (Véanse también làs sugestivas observaciones del trabajo "Discurso sin método sobre Descartes", por Luis Emilio Soto). Lo mismo, aproximadamente, que advierte también Jaspers, refiriéndose a este aspecto de Descartes: "En simplifiant schématiquement les choses et en considérant les âges de l'esprit comme des étapes nettes et bien déterminées - par exemple d'une part la scolastique médiévale, d'autre part l'esprit moderne- on ne saura où placer Descartes. Il ne représente aucunement la simple transition de la scolastique à la science moderne. Il est l'énigme d'une philosophie unique qui peut paraitre aussi bien scolastique que moderne, mais qui ne correspond à aucune de ces deux formes quoiqu'elle soit un tout, caractérisé d'ailleurs dans son cssence par l'équivoque". (4) Lo que, dicho sea de pasada, no es en sí mismo cosa muy moderna.

De los tantos ejemplos que pudieran tomarse como concreta ilustración de este tema de la modernidad o no modernidad de Descartes, es uno de los más típicos el referente a la actitud en que el distinguido filósofo aparece frente a las ciencias de la naturaleza, precisamente por ser estas ciencias y el espíritu cientifico a que deben, cuando no su origen, su portentoso desarro1lo, parte tan principalísima del pensar y el sentir modernos, a partir del Renacimiento. Por supuesto que no menos al tratar el señor Reulet de este aspecto de la cuestión, aparece Descartes en el punto de partida de las nuevas ciencias, junto su nombre al del gran Galileo, por ser la misma la actitud de ambos en este caso. Lo decisivo aquí, dícesenos, es la conciencia a que Descartes llega de la insuficiencia de la razón teológica y de la verdad revelada para arribar al conocimiento de la naturaleza. Era también una "razón natural" lo que para eso se necesitaba - exactamentc, "la razón que halló Descartes en sí mismo, en 
la intimidad de su conciencia" (p. 282). Esto, sin embargo, en principio exacto, deja fuera de consideración el hecho, para el caso más importante, de que por su tendencia a construir, no precisamente a investigar, la realidad desde dentro según un sistema de deducciones racionales, como exigido por el espíritu de su filosofía racionalista y un pocó acaso también por el orgullo de quien de antemano se cree en posesión de la verdad, igualmente que por la tendencia a hacer de la filosofía una a modo de ciencia única y universal de una realidad también única y universal - por todo eso es el cartesianismo lo más alejado, realmente lo opuesto, del espiritu científico moderno, que es todo él espiritu de investigación, observación y experimentación, y no en una suptuesta ciencia única y universal, ni con una invariable unidad de método, sino en variedad de campos científicos y en multiplicidad de especializaciones y según el método en cada caso más apropiado. Claramente subraya esta debilidad en la actitud científica de Descartes, por lo que a la física se refiere, el señor $\mathrm{J}$. Babini, en su interesante contribución al volumen que nos ocupa, "La matemática en Descartes y el mundo exterior". Reconocida, como es obligado, la gran significación de Descartes en la matemática, por lo que a la física respecta, "tampoco - -dice- respecto al significado de la experimentación, es Descartes actual. De la discusión suscitada acerca del papel de la experimentación en la física cartesiana, parecería desprenderse que Descartes, sin negarle importancia, no le reconoce, sin embargo, su verdadero valor científico, considerándola, más bien, como una guía que ha de facilitarle el descubrimiento de los principios racionales sobre los que fundamentará su física y que ninguna experimentación futura podrá modificar" (pp. 17-18). Este reconocimiento del significado $y$ valor de la experimentación da al espíritu científico moderno (el recibido de hombres como Galileo) una cuialidad de flexibilidad y de posibilidad, de horiżonte abierto, que contrasta con la nota de rígido dogmatismo (el dogmatismo de la razón como visión clara y distin* 
ta: sobrevivencias teológicas) inherente al espíritu de la filosofía cartesiana como al espíritu de todo el racionalismo, y que justifica el duro juicio pronunciado por Jaspers de que, como él dice, "les sciences de la nature évoluèrent en contradiction avec Descartes", resultando la influencia de éste en la historia de esas ciencias haber sido "nulle, inexistante ou même gênante". (5) "Gênante", porque lo que esas ciencias tuvieron que hacer para poder avanzar fué precisamente reaccionar contra esa tendencia latente en la filosofía cartesiana a las construcciones científicas de pura razón, especulativas, sin base, sin realidad. En una palabra, tuvieron que reaccionar contra los teóricos y el teorismo científico, para hacer lugar al investigador y al verdadero espíritu científico. Sin duda, porque mientras que para el científico los métodos son... eso, métodos, medios, caminos para llegar al conocimiento y a la verdad (verdad relativa), para Descartes el Método deja de ser medio y pasa a ser fin en sí mismo, y es de la verdad (verdad absoluta) dèl Método, vaciado ya de contenido propio, de lo que ante todo se trata. Se explica que ni Descartes ni el cartesianismo fueran nunca santos de devoción en el calendario de rituales prácticos y. empíricos del anglosajonismo.

Asi dejada de lado la modernidad de Descartes, por lo que a la restante parte de la tesis del señor Reulet se refiere, al hacer coincidir, como vimos lo hacía, Descartes y el americanismo, hay desde luego campo sobrado para que cada lector especule por sí sobre el particular y saque las conclusiones que estime más acertadas. Por nuestra parte hemos de confesar que nos resistimos a creer en una tal coincidencia y una tal ecuación de términos. Trataríase, según esa tesis, de reconocer en el americanismo las mismas dos notas destacadas por el autor en Descartes : la nota racionalista y la nota anti-tradicional. No parece, en efecto, que ni la historia política, ni la historia literaria; ni la historia cultural de Iberoamérica (damios por supttesto que en Iberoamérica estaría pensando el autor al establecer la coin- 
cidencia entre Descartes y el americanismo; por lo demás, no importaría mayormente para el caso que se tratara de una u otra América) justifiquen semejante interpretación del americanismo. Sería incluso un poco extraño, y hasta un tanto paradójico, que así fuera, tratándose como se trata de pueblos relativamente jóvenes: Porque la verdad es que ni racionalismo ni antitradicionalismo son estadiós por donde la vida empieza; son, por el contrario, estadios a que llega la cultura tras un muy largo proceso, un sí es no es en vísperas de vejez. 'Si la cosà fuera verdad, sería también un tanto desconsolador; habría que pensar en que pronto veríamos a algún Sócrates (lejano antecedente de Descartes) aparecer por las calles y plazas de Buenos Aires, y hasta a algún Descartes metido en alguna "estufa" (que no sería ya alemana).

$Y$ dejamos de lado todo cuanto aquí pudiera especularse subre el tan pintoresco tema de las herencias raciales, etc. Lo que ocurre es que el sentido tradicionalista, sin precisamente cambiar. de esencia, cambia de formas y de contenidos; pero en esto, como en religión, no se trata de sustituir ídolos, sino modos, actitudes espirituales. $Y$ bien pudiera ocurrir que lo cambiado en este caso no fuera tanto el sentido tradicional mismo cuanto los contenidos y objetos de la tradición. Aparte del hecho tan natural de que, por virtud de su misma juventud, los pueblos americanos se sientan más ligeros de andadura que los viejos pueblos europeos. Lo cual no obsta, es claro, para que América, la del Norte o la del Sur, sea todo lo avanzada, progresista y moderna que se quicra, pues también progresismo y modernismo caben dentro de la tradición y el espíritu tradicional, o por lo menos así parecen creerlo los ingleses. Por de pronto, acasó no sea la menor prueba de ese espíritu progresista y moderno de América el darse ya cuenta plena de que la hora del cartesianismo ha pasado. El propio señor Reulet, como dijimos, lo reconoce así. Y más enfáticamente aún, escribe el señor Luis Emilio Soto en su citado trabajo: "La cultura presente debe de. 
nunciar al cartesianismo y repeler lo que hay en él de pensamiento pre-histórico, vale decir, fosilizado" (p. 292). Si; Iberoamérica -habrá que concluir- se da cuenta perfecta, a la vez que de la modernidad de Descartes, de su radical inactualidad.

Necesitaríase ahora mucho más espacio del de que aquí podemós disponer para dar aunque sólo fuera una breve idea de cada uno de los restantes trabajos inclú́dos en el volùmen a que venimos refiriéndonos. Digamos, pues; tan sólo, que los temas mismos de esos trabajos abarcan un vasto campo del gran tema cartesiano en la múltiple variedad de sus aspectos: Filosófico ("El concepto de origen en la Metafísica y en la Ciencia", por Walter Blumenfeld; "Sentido y crisis del cartesianismo", por Jordán B. Genta; "Algunas aclaraciones sobre el Método Cartesiano", por Patricio J. Grau; "Breves reflexiones sobre el racionalismo de Descartes", por Mariano Ibérico; "El problema épistemológico en la filosofía de Descartes", por S. M. Neuschlosz; "El problema de las ideas innatas en Descartes", por Eugenio Pucciarelli, autor también de los trabajos "La causalidad en Descartes" y "La psicología de Descartes"; "El papel de Dios en la filosofía cartesiana", por Amalia H. Raggio; "En torno a Descartes, filósofo", por Sofía Suárez; "Regreso intencionado al punto de partida de Descartes: Conciencia y finitud", por Angel Vasallo), Psicológico ("Notas sobre la psicología cartesiana", por Leonardo Castellani), Etico ("Ensayo acerca de los valores en el cartesianismo", por Angélica Mendoza de Montero; "Elementos éticos en la filosofía de Descartes", por Raúl A. Piérola), Estético ("En torno a la estética de Descartes", por Alfonso Reyes), Religioso ("El pensamiento religioso de Descartes", por Emile Gouiran). La influencia de Descartes en el pensar filosófico inglés es objeto del trabajo "Descartes y la filosofía inglesa del siglo: XVII", por Risieri Frondizi. "Pascal y Voltaire contra Descartes", es el título y tema de un trabajo por Delia Ortiz Arigós de Montoya. El aspecto pedagógico es discutido en "Descartes y el ideal pedagógico francés", por 
Saúl Taborda. - En fin, last but not least, el inspirador del proyecto del homenaje a Descartes, el profesor Francisco Romero, es no menos autor de un trabajo que, por la actualidad del tema y calidad del estudio, es de valor fundamental: "Descartes y Husserl". Finamente señala el profesor Romero la similitud entre la finalidad perseguida por el filósofo francés y el filósofo alemán: "Se trata, para Husserl como para el filósofo francés, de una reedificación del conocimiento sobre cimientos de solidez indudable; de un pensar que se apoye en una base verdaderamente última y que nada deje tras si" ( $p$. 245). Ahora que, si la finalidad es semejante, los caminos son divergentes: "Descartes piensa en dirección al cogitante y Husserl en la de las cogitaciones. Mientras Descartes se interesa por el sujeto de los actos de conciencia, Husserl se atiene a la mera conciencia y empieza negando el yo como algo distinto del complejo de los actos mismos". (p. 255).

Constituye la publicación del volumen Homenaje a Descartes un honor tanto para el autor del proyecto y la Universidad Nacional de La Plata que lo aprobó y llevó a efecto como para los autores que en la realización de ese proyecto tomaron parte. Nos complacemos én recomendar el libro a la atención del lector.

\author{
César barja, \\ Universidad de California, \\ Los Angeles.
} vii, 201 .

(1).-P. Léon Veuthey, La pensé contemporaine, Paris (1938), pp. (2).- "La prensée de Descartes et la philosophie" en Revue Philosophique, Mai-Aout 1937, pp. 39-148.

(3)-Hauptprobleme der Phitosophic, Berlín, I920, pp. 28-29.

(4) - $-O$ p. cit., p. I35.

(5).-Op. cit., pp.: 140,95 . 